\title{
Normative Change Management Model in Covid-19 Pandemic
}

\author{
Dipak Kumar Bhattacharyya.,PhD \\ Professor, Xavier School of Human Resource Management, \\ Xavier Institute of Management, Xavier University, India \\ dkb@xub.edu.in, dkbhattacharyya@yahoo.co.in
}

\begin{abstract}
This paper proposes the need for a normative change management model in Covid-19 pandemic. The paper, at the outset, reviewed popular theoretical models for organizational change, elaborated the challenges now being faced by the organizations, and then developed the normative model, using change wheel. The proposed normative change management model is organic in nature, and hence cannot have universal applicability. In this pandemic situation, organizations can think of managing their change, based on their own assessment of change needs, rather than following any established prescriptive change management model. The paper is based on author's experience of managing several organizational changes successfully.

Keywords: Change Management, Change Strategies, Change Management Models, Normative Change Management Model
\end{abstract}

\section{Introduction}

Change is an ongoing process in any organization. In today's pandemic situation, every organization needs to plan for change, based on their strategies to sustain. Essentially organizational change is either transactional or transformational. But in pandemic situation, all organizational changes are transformational in nature. Unlike transactional changes, which focus on specific organizational issues, transformation changes are more holistic, as it encompasses the entire organization. In pandemic situation, transformational change requires effective use of change strategies, pacing with environmental trends. Such transformational change is more contextual in nature, as it primarily considers external and internal environmental forces, triggered by the recent pandemic situation.

Covid-19 and consequent pandemic requires organizations to go for embracing sustainable change approach, rather than planning for total restructuring, denoting reengineering. Although we observe many organizations temporarily changed their business focus, like; producing things which are not part of their core competencies, viz., hand sanitizer, masks, PPEs, hand gloves, etc.; these are primarily for ensuring cash flow to sustain. Some companies even gone to the extent of partnering with other organizations to provide supply chain and logistic support. Some even embraced contract manufacturing, becoming an outsourced partner for big houses. In all such cases, organizations run the risk of losing their brand identity. Obviously for such reason, it is desirable for organization to go for change in pandemic situation with normative approach, rather than blindly replicating any prescriptive change management model.

\section{Change Management Models}

Four pioneering prescriptive change management models, i.e., McKinsey 7-S Model, Lewin's Change Management Model,

The current issue and full text archive of this journal is available at http://jraspublications.org/index.php/JRAS/issue/archive Journal of Research in Administrative Sciences (JRAS)

IX(I), 19-21, ISSN: 2664-2433
Kotter's Eight Step Change Model, and ADKAR Change Model are popularly used by organizations to manage their change.

McKinsey 7S model focuses on achieving strategic fit of every change move of the organization, viewing change more holistically. For example, how change strategy fits with organizational structure needs require our prior understanding, else, prevalent structure of the organization may be an impediment in achieving the change intent. Similarly, organizations need to achieve fit of their change strategy with their prevalent systems or business processes, fit with shared values, with style, staff, and skills. Such fit of change plan can ensure consistency in organizational change, duly isolating any possible conflict of interests. For such complex inter-relationships between different Ss, can make the process of organizational change, with the use of this model, more difficult. Moreover, this model is more focused on rational constituents, rather than emotional aspects. Despite such shortcomings this prescriptive model is widely used in effecting organizational change.

Lewin's Change Management Model is again another popular prescriptive model of organizational change. Although developed in $1940 \mathrm{~s}$, this model is popular. Here again, organizational change is viewed as a mechanical process, as it totally ignores people issues. This model was developed by Lewin replicating the analogy of change in the shape of an ice block. For example, to change the shape of an ice block, to fit in a cone, we need to melt it (the stage of unfreezing), and then refreeze it for getting the cone shape. Hence, unfreezing, changing, and refreezing, have been stated by Lewin for adherence to bring change in organizations. This model's popularity is more for its simplicity, however, without consideration of people issue, the model, like the earlier case, become more mechanical. 
Kotter's 8-step Model of Change, in contrast to two earlier models, emphasizes more on people issues. In fact, the model envisages participation of people in the change process is more important. Eight distinct stages like; urgency for change, building team for change, constructing the vision, communicating, empowering, creation of short-term goal, and persistency, when adhered to can bring positive change in organization. However, in current pandemic situation, this model may be a luxury, as it is time consuming.

ADKAR Change Model is based on organizational research. ADKAR stands for awareness, desire, knowledge, ability, and reinforcement. The model emphasizes time investment for each such stage, so that change intents can be achieved. With a steppedup approach, this model can optimize the time requirement. However, it may not be universal, as depending on the organization, composition of workforce, the model may not work.

More recent model like McKinsey's Influence Model, which is again based on academic research, emphasizes on; fostering of understanding and conviction, reinforcement with formal mechanism, development of talent and skills, and role modeling. Even though the model is agile, it is more appropriate for technology intensive organization, which engages knowledge workers.

\section{The Normative Change Management Model}

For managing change, it is wrong to assess which model can be good, or which model can be right-fit, as organizational change issues widely vary. Hence for absence of universalistic approach, we need to decide our normative change management approach, specific for an organization. This is also known as organic change management model or approach, as it evolves within a specific organization. In most of my change management assignments, it was observed, organizational change issues are transformational in nature, which requires more critical understanding to draw the action plan. Transactional change issues are limited in scope, and can be managed at departmental level, without much of resistance from employees.

Covid-19 pandemic situation now complicated organizational change issues, as for most of the organizations, these change issues are transformational, requiring organizational restructuring and reengineering.

Let us first examine some immediate challenges for organization for this change crises:

1. Time constraint - Organization need to act quickly. Delayed response may ruin them.

2. Centralized decision - Centralized decision is important, as decision making process should be very fast. Also, participative decision may disrupt the change process for obvious disagreement.

3. Balanced power coercive and rational-empirical approach This depends on the profile of people engaged by the organization. For low skilled and low-profile jobs, it may be desirable to go for power coercive approach, even though sounds inhuman and ruthless. For knowledge workers, rationalempirical approach may work. But in such a crisis, we rather follow a balance between these two approaches. Even knowledge workers may not agree with the change plan, despite having merit.

4. Poor cash flow - More focus is necessary for internal cash generation, saving internal costs. Such costs are not necessarily pay cut alone. It may be even be optimization of various overhead and other costs, like; reduced office space, salvaging of idle inventories, savings on electricity, transport, canteen, etc.

5. Sustaining brand identity - Often many organizations, to manage their cash flow, start doing sub-contracted jobs of other organizations, even to the extent of doing jobs of their competitors, loosing product traceability at the customer end. For example, a small FMCG company, which already have established brand may engage in producing products of a large
FMCG company, which is their competitor, losing their brand identity. Such a move earlier was laudable, as it helps in maintaining the cash flow; but in today's context, if we examine, this is not at all desirable, as in this process the company doing sub-contracted jobs of their competitors may loose their brand identify.

6. Pay-cut for all rather than reducing the head counts - This is a debatable issue. We find many organizations have ruthlessly reduced their headcounts, particularly in the lower rung; while for others, they went for pay cut of varying percentage. There is an underlying fear that they may lose the talent. Better alternative could be to go for equitable distribution of available resources. Raise the pay cut for seniors and ensure that all members of the organizations are given atleast some wages for sustenance. This can develop the team spirit, togetherness, and the zeal to remain loyal with the company.

Our normative or organic change management model considers all the above challenges that are now being faced by the organization, and suggest six-step approach as under

Step-1 - Ice breaking to help people understand change need better. Use both formal and informal communication with one single message on need for change.

Step-2 - Helping people to relate using appreciative inquiry, i.e., strength-based approach to effect change. Organizations at this stage commit mistake to sensitize people with the negative consequences if people decide not to change.

Step-3 - Make people informed through empowerment, i.e., making people capable to understand the change need, so that they can make an informed choice. This is done through capability development programme. If people are not in workplace, then go for virtual programme.

Step-4 - Follow the principle of mutuality with a Venn diagram to show how both employer and employees' issues converge.

Step-5 - Let people be a party to change by asking for their suggestions after discussing company's stand in this crisis. If required make alteration to your plan, so that people can identify them better with the change plan.

Step-6 - Set incremental change plan to capture the results to showcase to people something positive is happening. Incremental or short-term change results are easier to achieve. Such positive outcome can spark the motivation of people to participate in change process more vigorously. This can set the momentum for change.

The model is illustrated below:

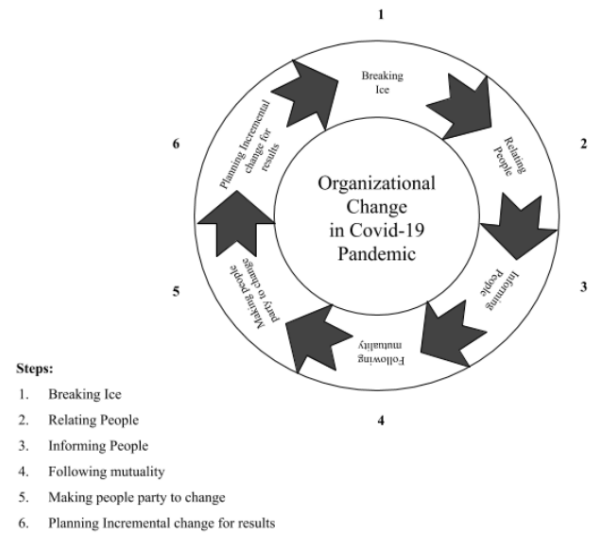

\section{Conclusion}

The normative model of organizational change provides equal importance or opportunity to all cross-sections of people of the organization. When this model is applied, every member of the 
organization enjoys a sense of ownership. It makes use of group process for performance and accountability of behaviours of the members of the organization, ensures shared vision, and makes the organization physically and emotionally stable. Even though normative-re-educative approach of organizational change is the right way for making people accept organizational change process as an informed choice; in this pandemic situation we require organization specific action plan to churn around with agility. This suggestive model is based on author's experience, and not a universal approach.

It is inappropriate to assume that complying with this normative model of change, by default will give us the success. This model may not work when the nature of change requires us to make people redundant, scaling down activities, and power coercive strategies. In transformational change management cases, this model can certainly help, as it works with minimum dissension and resistance from people.

\section{References}

i. Ackerman, L.S. (1986). "Development, Transition or Transformation: The Question of Change in Organizations". Organizational Development Practitioner, Vol. 18 No. 4, pp. $1-9$.

ii. Balnaves M. and P. Caputi. (1993). "Corporate Constructs: To What Extent are Personal Constructs Personal"? International Journal of Personal Construct Psychology, Vol. 6, No.2, pp. 119-39.

iii. Beckhard, R. and R.T. Harris (1987). Organizational Transitions. Reading: Addison-Wesley.

iv. Bhattacharyya, Dipak Kumar. (2007). Human Resource Research Methods. New Delhi: Oxford University Press.

v. Bhattacharyya, Dipak Kumar. (2011). Organizational Change and Development. New Delhi: Oxford University Press.

vi. Bhattacharyya, Dipak Kumar (2014). Organizational Behaviour, second edition. New Delhi: Oxford University Press.

vii. Checkland, P. (1981). Systems Thinking: Systems Practices. New York: Wiley.

viii. Cummings, T.G. and C.G. Worley (2005). Organization Development and Change, eighth edition. Mason: SouthWestern Publishing.

ix. Dallos R. (1991). Family Belief Systems, Therapy and Change. Milton Keynes: Open University Press.

x. Dawson, S.J.N.D. (1996). Analysing Organizations. Hampshire: Macmillan.

xi. Kanter, R.M. (1983). The Change Masters: Innovation and Entrepreneurship in the American Corporation. New York: Simon and Schuster.

xii. Kanter, R.M. (1989). When Giants Learn to Dance. New York: Simon and Schuster.

xiii. Kanter, R.M. (1995). World Class: Thriving Locally in the Global Economy. New York.

xiv. Kanter, R.M. (2001), Evolve! Succeeding in the Digital Culture of Tomorrow. Boston: Harvard Business School.

xv. Kelly G.A. (1991). The Psychology of Personal Constructs. London: Routledge.

xvi. Kotter, J. (1995). "Leading Change: Why Transformation Efforts Fail”, Harvard Business Review, Vol. 73, No. 2, pp. 59-67.

xvii. Lewin, K. (1951). Field Theory in Social Science. New York: Harper and Row.

xviii. Mintzberg, H. (1989). Mintzberg on Management: Inside Our Strange World of Organisations. Chicago: Free Press.

xix. Nadler, D. and M. Tushman (1989). "Organizational Frame Bending", Academy of Management Executive, Vol. 3, No.3, pp. 194-204.

xx. Nadler, D.A. (1993). Concepts for the Management of Organizational Change, in C. Maybe and B. Mayon-White (eds), Managing Change, 2nd ed. London: Paul Chapman. pp. 85-98

xxi. Pasmore, W. and M. Fagans (1992). "Participation, Individual Development, and Organizational Change: A Review and Synthesis", Journal of Management, Vol. 18, No. 2. pp. 375-397.

xxii. Popper, K. (1972). Objective Knowledge. Oxford: Oxford University Press.

xxiii. Procter H. (1981). "Family Construct Psychology", in S. Walrond-Skinner (ed.), Family Therapy and Approaches. London: Routledge and Kegan Paul.

xxiv. Ravenette T. (1977). Selected Papers: Personal Construct Psychology and the Practice of an Educational Psychologist. Famborough: EPCA Publications.

xxv. Sashkin, M. and W. Burke (1987). "Organization Development in the Nineteen-eighties". Journal of Management, Vol. 13, pp. 393-417.

xxvi. Schein, E.H. (1992). Organizational Culture and Leadership. San Francisco, CA: Jossey Bass Publishers.

xxvii. Senge, P.M. (1990) "The Leader's New York: Building Learning Organizations", Sloan Management Review, Fall, pp. 7-23.

xxviii. Tschudi F. (1977). "Loaded and Honest Questions", in D. Bannister (ed.), New Perspectives in Personal Construct Theory. London: Academic Press.

xxix. Weick, K.E. and R.E. Quinn (1999). "Organizational Change and Development". Annual Review of Psychology, Vol. 50, pp. 361-86.

xxx. Woodman, R. (1989). "Organization Change and Development: New Arenas for Inquiry and Action". Journal of Management, Vol. 15, pp. 205-228.

xxxi. Woodward, N.H. (2007). "To Make Changes, Manage Them". HR Magazine, Vol. 52, No. 5, pp. 63-7.

Author: Prof. D.K. Bhattacharyya

Prof. D.K. Bhattacharyya is Ph.D. in Management from University of Calcutta. He has served in industry in Training and Organizational Development function for 15 years. Thereafter for last two and half decades he has worked with several Management Institutes in India in various capacities like; Director, Dean, Head of the Department, Professor, etc. Presently he is working as Professor of Xavier Institute of Management, Bhubaneswar, India. $\mathrm{He}$ is also a visiting faculty of XLRI, Jamshedpur, and IIM, Kozhikode. Prof. Bhattacharyya has extensive consultancy experience in HR, Quality Management, Human Resource Planning, Compensation Design and Organizational Change and Development, Organizational Design and Restructuring areas. He has published 30 Books on HR management areas with Sage, Oxford, Pearson, PHI, Cengage, University Press, IGI Global etc., and has contributed more than 100 papers in various journals of national and international repute. His primary area of research interest is on Human Capital Management and Organizational Change and Development. 